\title{
INVESTIGAÇÃO EPIDEMIOLÓGICA DE UM NOVO CASO DE LEISHMANIOSE VISCERAL OCORRIDO NA GRANDE SĀO PAULO, BRASIL *
}

Lygia Busch lversson ** Raquel B. Robert Pires *** Maracy Alves Ribeiro*** Augusta K. Takeda *** Alvaro Escrivão Júnior ***** José Eduardo Tolezano **: Geraldo Magela Buralli *****

IVERSSON. L. B. th al Investiga(âa epidemiologica de um novo caso de leishmaniose visceral ocorrid", na Grande São Paulo, Brasil. Rev. Saúde públ., S. Paulo, 16: $205-19, \quad 1982$.

RESUMO: Descreve-se uma investigação epidemiológica realizada em zona urbana do município de São Paulo, Brasil, para esclarecer um caso de leishmaniose visceral ocorrido em criança de 2 anos de idade, nascida e sempre residente no local. Afastou-se a possibilidade de transmissão por via transfusional e por vetor biológico, tendo como base os dados levaritados da anamnese do doente, os resultados de inquéritos realizados na área em população huniana, utilizando testes de imunofluorescência indireta, hemaglutinação passiva $e$ intradermoreação de Montenegro, em população canina com o teste de imunotluorescência indireta, além de pesquisa entomológica em mata residual.

CNITERMOS: Leishmaniose visceral, vigilância epidemiológica.

\section{INTRODUCAO}

En agosto de 1978 foram notificados às autoridades sanitárias de São Paulo dois casos de leishmaniose visceral em crianças menores de 2 anos de idade que sempre residiram na área metropolitana da Grande São Paulo. A investigação epidemiológica cesses casos afastou a possibilidade de transmissão congênita da moléstia nos dois doentes e a de transmissão por transfusão sanguínea em um deles (Secretaria de Estado da Saúde de São Paulo, 1978 *; Iversson e col.2:', 1979). Configurava-se a existência na região.

Apresentado no VII Congresso da Sociedade Brasileira de Parasitologia. realizado em Porto Alegre, em 1982 .

* Do Departamento de Epidemiologia da Factildade de Saúde Pública da USP . Ar. Dr. Arnaldo. 715 - 01255 - São Paulo, SP - Erasil.

** Do Instituto Adolfo Lutz - Av. Dr. Arnaldo, 355 - 01255 . Sāo Paulo, SP - Brasil.

\#*** Da Secretaria de Estado da Saúde de São Paulo - Rua Conselheiro Nébias, 1355 - 01203 - São Paulo. SP - Brasil.

H:*** Da Superintendência de Controle de Endemıas - Rua Tamandaré, 693 -- 01525 -- São Paulo, $\mathrm{SP}-$ Brasil. 
IVERSSON, L.B. et al. Investigação epidemiol ógica de um novo caso de leishmaniose visceral ocorrido na Grande Săo Paulo, Brasil. Rev. Saúde públ., S. Paulo, 16:205-19, 1982.

fato inédito, de uma estrutura epidemiológica que permitia a circulação da Leishmania donovani em um ciclo natural que envolvia o hospedeiro humano.

Esses pacientes, na verdade, pareciam representar a parte revelada de um todo onde deveriam existir outros casos, sub-clínicos ou clínicos não diagnosticados. Um inquérito em que se utilizaram provas de imunofluorescência indireta, hemaglutinação passiva, fixação de complemento e a intradermoreação de Montenegro, realizado em grupo populacional residente próximo a um dos pacientes, revelou a presença de 3 crianças, aparentemente sadias, com provas sorológicas e reação de Montenegro condizentes com o diagnóstico de leishmaniose visceral subclinica (Iversson e col.22, 1979).

A existência de mata residual próxima sugeria a possivel presença, não confirmada em algumas capturas efetuadas em outubro de 1978, da Lutzomyia longipalpis, considerada o principal vetor da moléstia no continente americano. No entanto, não foram conduzidas, recentemente, pesquisas entomológicas continuadas nessa como em outras matas residuais da Grande São Paulo. Não se dispunha, porisso, de elementos para concluir sobre a ausência ou presença desse diptero, já identificado em Salto de Pirapora, Cássia dos Coqueiros, Pirapora do Bom Jesus, outros municipios do Estado de São Paulo (Forattini e col.19,20, 1970, 1976). Há, no entanto, em 1912, uma referência de Lutz e Neiva ${ }^{26}$ (1912) à sua presença, durante vários anos, no bairro do Bosque da Saúde, municipio de São Paulo, localidade -- tipo da espécie.

Os eventos humanos poderiam voltar a se repetir porque a transmissão natural da L. donovani ocorrida em 1978, em um dos casos mencionados, poderia não representar apenas um evento raro resultante da vinda ocasional para a área de um cão infectado. Também persistiam condiçōes para a ocor- rência de doença pós transfusional. De fato, em novembro de 1980 , um novo caso de leishmaniose em uma criança de 2 anos de idade, sempre residente no município de São Paulo, um dos 37 municipios da Grande São Paulo, foi notificado às autoridades sanitárias por clínicos que diagnosticaram a moléstia e trataram o paciente. Aspectos da evolução clínica e das primeiras providências tomadas pelos notificantes, para elucidar a fonte de infecção, foram descritas em publicação anterior (Amato Neto e Blanco Filho:, 1981).

$O$ presente trabalho relata a investigação epidemiológica realizada com o objetivo de esclarecer o problema e indicar as medidas profiláticas.

\section{METODOLOGIA}

Depois da verificação do diagnóstico, estabelecido após isolamento da Leishmania donovani de material medular, foram realizadas investigações junto ao hospital, onde se encontrava internado o paciente, e na residência do mesmo, obtendo-se as seguintes informaçōes:

O doente F. O., de 2 anos de idade, nasceu em 27/9/78, no municipio de São Paulo, nunca tendo dele se afastado. Nascido de parto hospitalar, o paciente esteve internado 7 vezes em 4 hospitais diferentes, com sintomatologia pulmonar, durante as quais recebeu, em 6 ocasiões $(30 / 3 / 79,3 / 4 / 79$, $4 / 8 / 78,17 / 10 / 80,18 / 10 / 80$ e $25 / 10 / 80$ ), transfusões sangüineas. As três últimas foram realizadas um dia antes ou após a data da confirmação da leishmaniose visceral, $18 / 10 / 1980$.

A mãe de $F$. O. nasceu em zona rural de Governador Valadares, Estado de Minas Gerais, e morou em zona urbana de Belo Horizonte e São Paulo. Recebeu há 6 anos uma transfusão sanguínea.

A residência do paciente está situada no bairro de Capão Redondo, sub-distrito de

* Dados não publicados. 
IVERSSON, L.B. et al. Investigação epidemiológica de um novo caso de leishmaniose visceral ocorrido na Grande São Paulo, Brasll. Rev. Saúde públ., S. Paulo, 16:205-19, 1982.

Capela do Socorro, Município de São Paulo (Figura 1). Trata-se de um dos precários barracos de madeira de uma favela construída no alto e na encosta de um morro, em meio à vegetação pouco densa formada por elementos de pequeno porte, principalmente bananeiras (musa paradisiaca). Situa-se há aproximadamente $1.500 \mathrm{~m}$ dos limites de uma área de $1.250 .000 \mathrm{~m}^{2}$ pertencente a uma instituição de ensino, ocupada em parte por mata residual. Entre essa área, localizada também em elevação, e a favela se estende um vale onde se observam espaços livres revestidos por vegetação rasteira e espaços preenchidos por denso casario (Figuras 2, 3,4 e 5 ).

O sub-distrito de Capela do Socorro ocupa no município de São Paulo uma

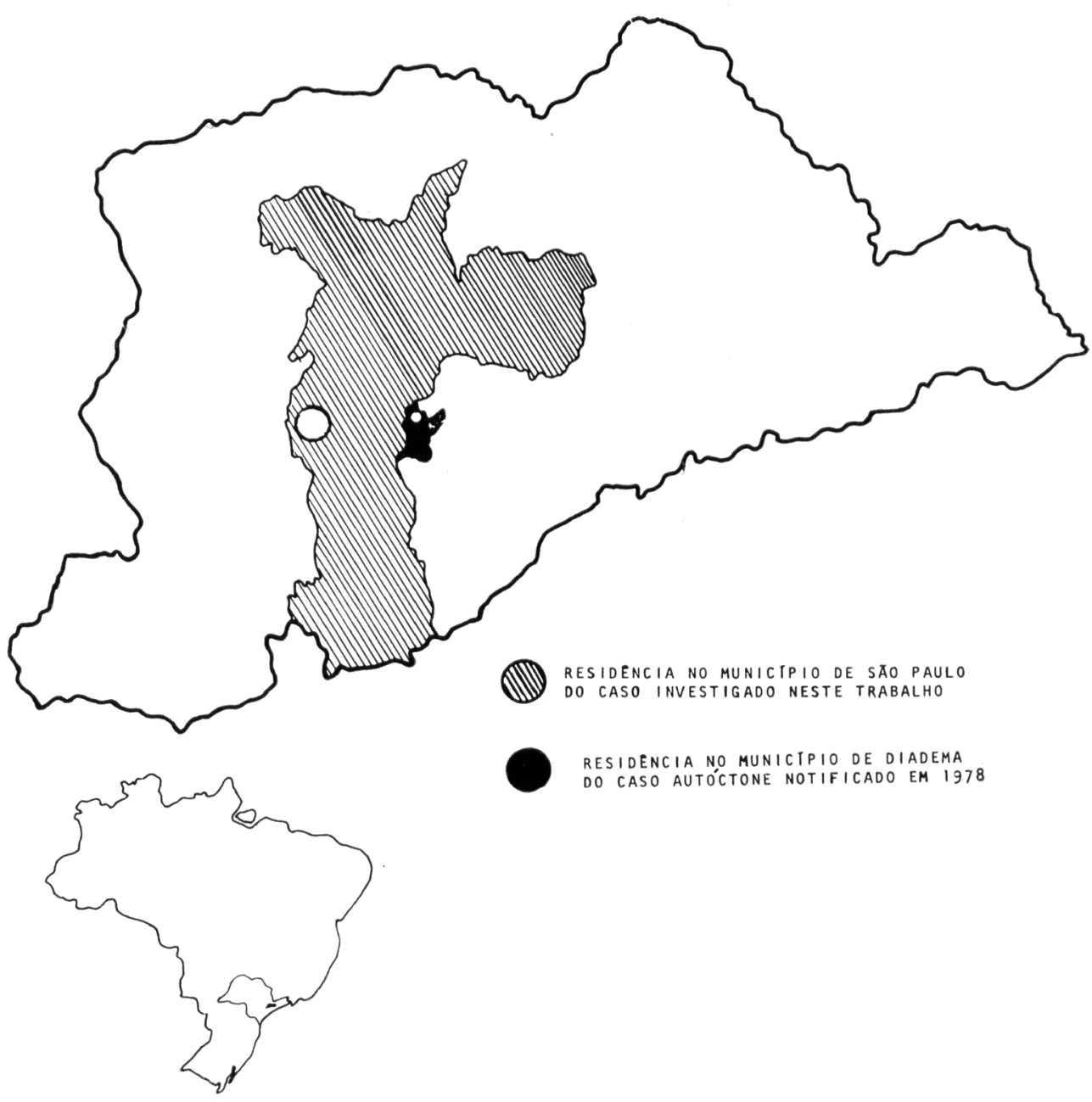

Fig. 1 - Localização geogrática da residéncia dos casos de leishmaniose visceral ocorridos nus municípios de São Paulo e de Diadema, área da Grande Săo Paulo. 
IVERSSON, L.B. et al. Investigação epidemiológica de um novo caso de leishmaniose visceral ocorrido na Grande São Paulo, Brasll. Rev. Saúde públ., S. Paulo, 16:205-19, 1982.

área de $151,06 \mathrm{~km}^{2}$, com uma taxa de urbanização de $95,93 \%$. Esse município, situado a uma altitude de $792 \mathrm{~m}$, apresenta uma temperatura média anual de $18,8 \circ \mathrm{C}$, temperatura média do mês mais quente de $21,6 \circ \mathrm{C}$, temperatura média do mês mais frio de $15,2^{\circ} \mathrm{C}$ e umidade média relativa de 80 HR\% 34,35 .
Diante dessas informações procurou-se investigar as mais prováveis vias de transmissão da moléstia: natural por vetor biológico, por via congênita e por transfusão de sangue.

A transmissão direta de canídeos ao homem, teoricamente possível tendo em vista o intenso pasitismo cutâneo nestes animais

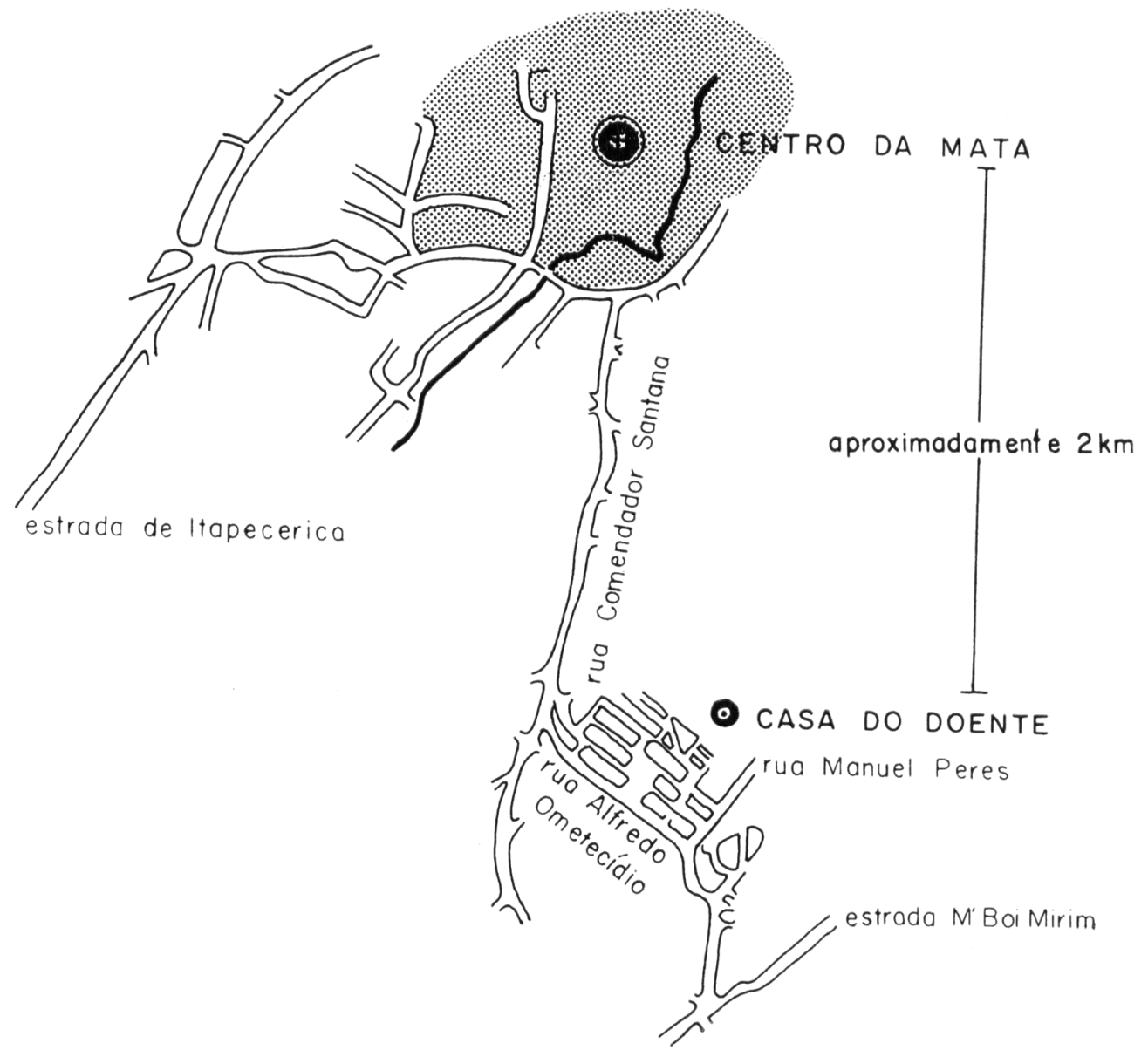

Fig. 2 - Localização da casa do paciente com leishmaniose visceral em relaçăo a mata residual. 


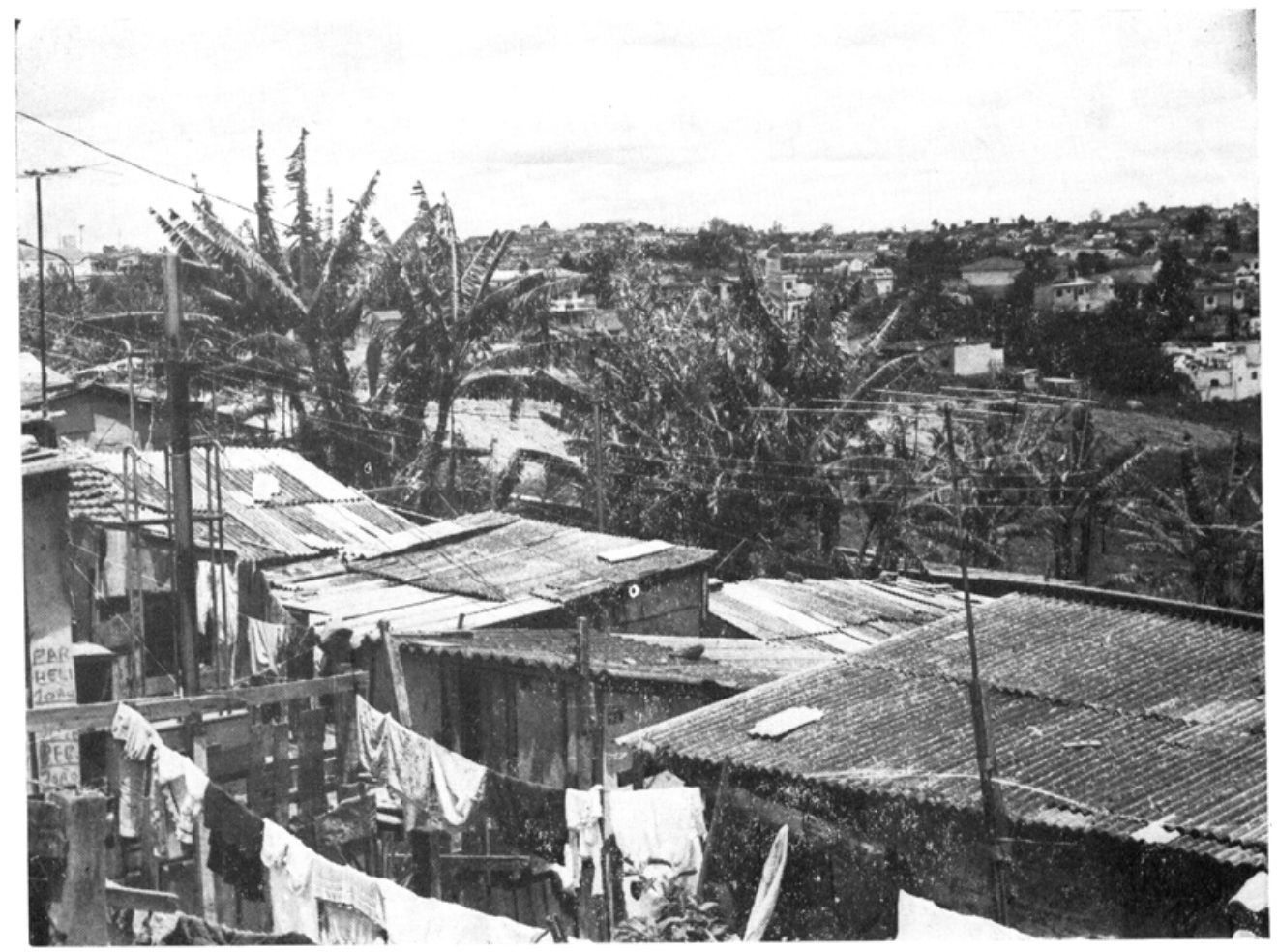

Fig. 3 - Local da residência do doente observando-se a topografia acidentada, a vegetação e
o aspecto precário das habitações.

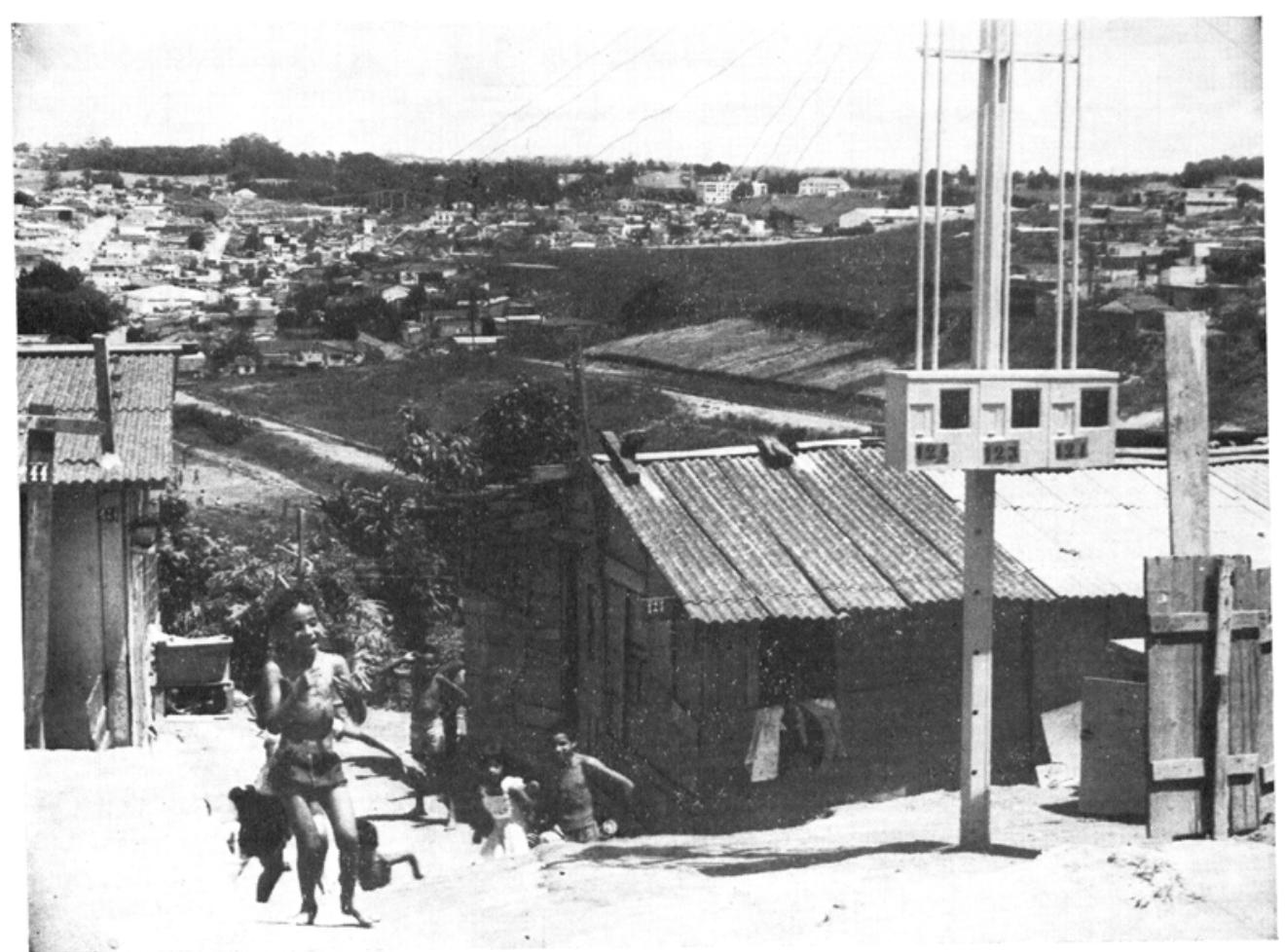

Fig. 4 - Vista dal mata residual, no horizonte, quando observada do local onde reside a paciente. 
IVERSSON, L.B. et al. Investigação epidemiológica de um novo caso de leishmaniose visceral ocorrido na Grande São Paulo, Brasil. Rev. Saúde públ., S. Paulo, 16:205-19, 1982.

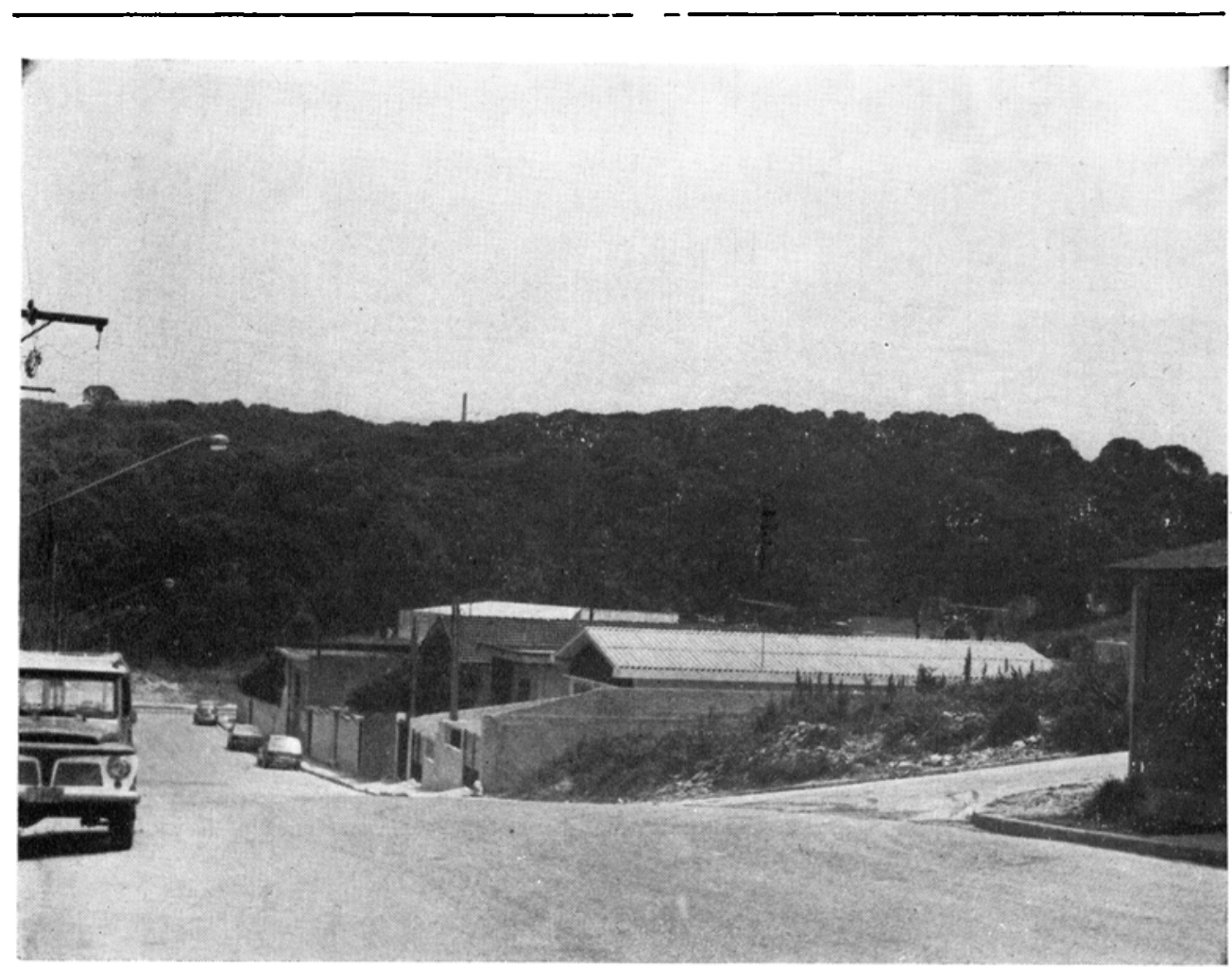

Fig. 5 - Aspecto externo da mata residual referida na Figura 4.

(Deane e Deane ${ }^{4}$, 1955), não tem apresentado significado epidemiológico.

Para verificar a possibilidade de transmissão congênita, realizaram-se na mãe da criança exame clínico e provas sorológicas de imunofluorescência indireta (IFI) e hemaglutinação passiva (H.A.) com antígenos de $L$. donovani.

Afim de esclarecer uma possivel transmissão transfusional coletaram-se informações que permitissem localizar os doadores das 3 primeiras transfusões de sangue e as outras pessoas que haviam recebido sangue proveniente dos mesmos frascos que foram utilizados no doente.

Para averiguar a eventualidade de transmissão natural, procedeu-se a inquéritos sorológicos em população humana e canidea $\epsilon$ à pesquisa entomológica em mata próxima.
Inquérito sorológico em população humana

Coletaram-se amostras de sangue por punção digital profunda em papel de filtro de 344 pessoas residentes na favela. Para eluição das amostras foram recortados discos de $2 \mathrm{~cm}$ de diâmetro. A quantidade de sangue coletada de cada indivíduo foi calculada por diferença de pesos, em miligramas, dos discos impregnados de sangue e do mesmo volume de discos não impregnados. Os discos foram imersos em volumes calculados de solução tamponada fosfatada (STF), pH 7,2, necessários para a obtenção de amostras diluídas a $1 / 20$, que foram em seguida analisadas em diluição dobradas, pelas provas de imunofluorescência indireta (IFI) e hemaglutinação passiva (H.A.), utilizando-se antígenos de $L$. donovani, $L$. braziliensis e $T$. cruzi. 
IYERSSON, L.B. et al. Investigação epldemiológica de um novo caso de leishmaniose visceral ocorrido na Grande Săo Paulo, Brasil. Rev. Saúde públ., S. Paulo, 16:205-19, 1982.

As pessoas pesquisadas representavam $69 \%(344 / 495)$ dos moradores da faveli, dos quais $65 \%(225 / 344)$ eram menores de 15 anos de idade e $25 \%(85 / 344)$ eran menores de 5 anos. Residiam em 146 barracos agrupados em dois conglomerados num raio de $200 \mathrm{~m}$ em torno da casa do doente. Uma proporção de $95 \%$ dos residentes $(470 / 495)$ foi submetida a exame físico, visando observar principalmente a presença de adenopatias e hepatoesplenomegalia. Aplicou-se a essas pessoas um questionário em que se pesquisou a idade, naturalidade, tempo de residência no local, outros locais de moradia e antecedente conhecido de leishmaniose, moléstia de Chagas, malária, esquistossomose, tuberculose e hanseníase.

Nas 42 pessoas que apresentaram algum título nas provas sorológicas foi realizada em junho de 1981 uma segunda coleta de sangue, por punção venosa, e se repetiram as provas. Nessas pessoas e nos que com elas coabitavam, 92 pessoas no total, efetuou-se a intradermoreação de Montenegro.

Nos soros que apresentaram titulos compativeis com diagnóstico de leishmaniose reálizaram-se testes de inibição da hemaglutinação e de hemaglutinação passiva para $L$. donovani depois das amostras de soro terem sido absorvidas $\operatorname{com} L$. donovani, $L$. braziliensis e $T$. cruzi.

Para as provas de imunofluorescência indireta, foram utilizadas como antígeno formas epimastigotas de $T$. cruzi cepa $\mathrm{Y}$ e promastigotas de $L$. donovani e $L$. braziliensis, cultivadas em meio de Salles Gomes (Salles Gomes ${ }^{33}, 1960$ ) a $28{ }^{\circ} \mathrm{C}$ durante 5 a 7 dias. A leitura foi feita em microscópio de epi iluminação Standard 18 Zeiss para jmunofluorescência com filtro excitador FITC, barreira BG53 com lâmpada de halogênio $100 \mathrm{~W}$ e $12 \mathrm{~V}$. Foram considerados positivos os soros que apresentaram título a partir de 40.

As provas de hemaglutinação para a pesquisa de anticorpos contra $L$. donovani $\mathrm{e}$ $T$. cruzi foram realizadas conforme descrito por Hoshino-Shimizu, S. e col.21 (1978). Para o preparo desses antígenos, foram usadas formas epimastigotas de $T$. cruzı cepa $\mathrm{Y}$ e promastigotas de $L$. donovani, obtidas por culturas em meio LIT, Liver Infusion Triptose (Fernandes e Castellani ${ }^{17}$, 1966 ), a $28^{\circ} \mathrm{C}$ durante 7 a 10 dias. Foram considerados positivos os soros reagentes em diluições a partir de $1 / 160$, e duvidosos os que apresentaram titulo igual a 80 .

Para o teste de inibição de hemaglutinação utilizou-se como inibidores os extratos antigênicos solúveis de $T$. cruzi e $L$. aonovani. Cada antígeno foi misturado com c próprio diluente da reação (STF $\mathrm{pH} 6,4)$, em quantidade suficiente para uma concentração final idêntica àquela utilizada para a sensibilização das hemácias. A concentração desses antígenos foi determinada tomando como referência seu conteúdo protéico, dosado através do método de Lowry e col.25 (1951).

Para o teste de Montenegro foi utilizada suspensão ultrassonada de leishmanias em salina fluoretada fenicada contendo 22,98 $\mathrm{mg} / \mathrm{ml}$ de proteína. Foi aplicado, intradermicamente, $0,1 \mathrm{ml}$ desta suspensão na superfície de flexão do antebraço esquerdo, sendo a leitura efetuada após 72 horas. A positividade da reação foi indicada pela formação de vesícula, pápula ou área de infiltração perceptivel pelo tato com diâmetro $\geqslant$ a $8 \mathrm{~mm}$.

\section{Inquèrito sorológico em populą̧ão canina}

Foram pesquisados anticorpos para $L$. donovani, $L$. braziliensis e $T$. cruzi por teste de imunofluorescência indireta em 14 cães pertencentes a familias em que pelo menos um dos componentes tivesse apresentado titulo nas provas de I.F.I. e H.A. Em um dos animais que apresentou anticorpos para $L$. donovani em título baixo, procedeu-se à pesquisa do parasita em material de biópsia de pele de orelha, pelo exame direto (impressão em lâmina) após cultura em meio de Ducrey e após inoculação em hamsters (Mesocricetus autoratus), sacrificados após trinta e sessenta dias. 
IVERSSON, L.B. et al. Investigação epidemiológica de um novo caso de leishmaniose visceral ocorrido na Grande São Paulo, Brasil. Rev. Saúde públ., S. Paulo, 16:205-19, 1982.

\section{Pesquisa entomológica}

Foi realizada pesquisa entomológica na mata residual próxima tendo sido efetuadas três capturas com Barraca de Shannon, ém 27/11/80,28/1/80 e 23/2/80, no horário vespertino e noturno, em dias de tempo bom, sem vento, umidade relativa acima de $80 \mathrm{HR} \%$. Não foi obedecido programa previamente traçado.

\section{RESULTADOS}

\section{Investigação de transmissão congênita}

O exame físico da mãe de F.O. foi normal. Os testes de I.F.I. e H.A. foram negativos (soros não reagentes). $O$ exame físico dos seus outros 4 filhos de $3,6,8$ e 10 anos foi normal. Os testes sorológicos dessas crianças foram negativos (soros não reagentes).

\section{Investigação de transmissão transfusional}

Os endereços residenciais dos três doadores dos sangues transfundidos em 20/3/79, $3 / 4 / 79$ e 4/8/80 foram exaustivamente investigados.

L.J.C. residente no bairro do Ipiranga, município de São Paulo, não foi localizado no endereço mencionado; para a localização de N.F., residente no município de Mauá, foram percorridas 16 ruas que apresentavam c mesmo nome, não tendo sido encontrado o doador; em relação a C.A.R., residente no bairro Americanópolis, municipio de São Paulo, foram percorridas as duas ruas do local que têm a denominação constante do endereço, com resultados negativos.

Procurou-se também investigar nos Bancos de Sangue a existência de outras pessoas que houvessem recebido sangue dos mesmos frascos utilizados nas transfusóes de F.O. O frasco de sangue de L.J.C. não foi utilizado em nenhuma outra transfusão. $O$ sangue de N.F. foi transfundido também em um menor de 6 meses de idade que apresentava broncopneumonia, gastroenterocolite e desidratação de $2^{\circ}$ grau e que faleceu
7 dias depois da transfusão. $O$ sangue de C.A.R. foi também aplicado em $3 / 8 / 79 \mathrm{em}$ uma paciente adulta, com diagnóstico de carcinoma de intestino, que evoluiu para obito em 18/8/79.

\section{Investigação de transmissão natural}

Inquérito sorológico em população humana. Entre os 344 investigados, 15 pessoas apresentaram titulos positivos nos dois testes realizados ou em um deles para $L$. donovani, L. braziliensis e T. cruzi. Entre esses, 5 pessoas apresentaram títulos condizentes com infecção por leishmania, cujos resultados estão expressos na Tabela 1. As outras 10 pessoas apresentaram ou só título para T. cruzi ou título 4 vezes maior para esse hemoflagelado.

Observa-se na Tabela 1 que os resultados positivos referem-se em geral ao teste de hemaglutinação e que ocorreu em C.C.S., S.F. e D.S. uma queda nos titulos entre as duas amostras colhidas com 5 meses de intervalo.

Um fato de interesse epidemiológico é que C.C.S., A.L.M. e S.F. nasceram e sempre viveram no município de São Paulo, em bairros próximos, estando residindo no atual local de residência há 5,4 e 1 anos, respectivamente. L.C.L., de 25 anos, e D.S., de 50 anos, são naturais da Bahia morando no local há 3 e 4 anos, respectivamente. A.L.M. é vizinha do doente e as demais moram a $100 \mathrm{~m}$ do doente.

O exame físico das 5 pessoas foi normal, não se observando adenopatias, esplenomegalia ou hepatoesplenomegalia.

Para tentar eliminar reatividade sorológica heteróloga foram realizados testes de inibição de hemaglutinação e hemaglutinação passiva após absorção dos soros com antígenos totais de $L$. donovani, $L$. braziliensis e $T$. cruzi. Os resultados (Tabelas 2 e 3 ) evidenciam que os títulos diminuiram 4 vezes ou mais na reação de hemaglutinação após absorção dos soros por $L$. donovani e $L$. braziliensis e não se alteraram, ou apresentaram diminuição menor quando os soros foram absor- 


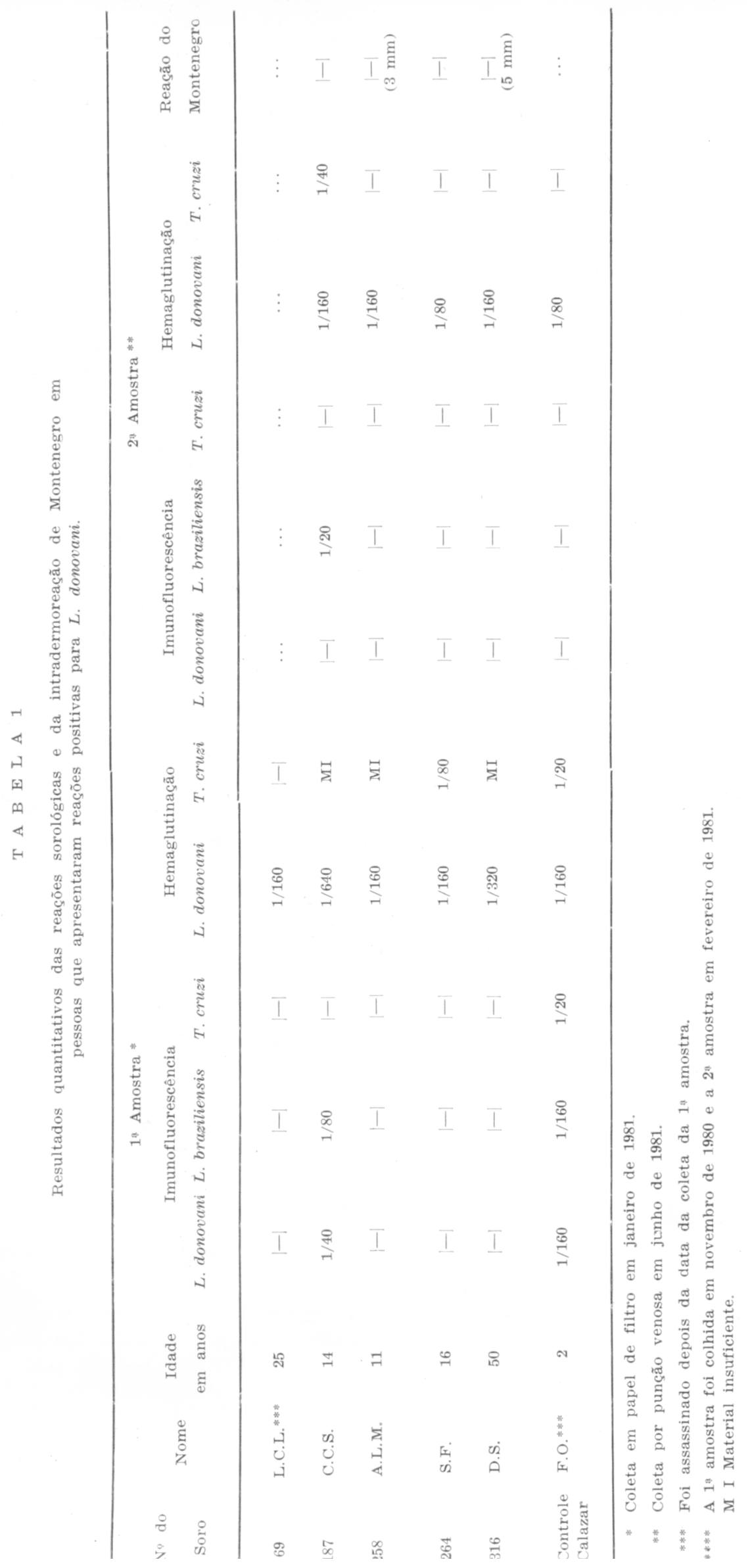


IVERSSON, L.B. et al. Investigaçăo epidemiológica de um novo caso de leishmaniose visceral ocorrido na Grande São Paulo, Brasil. Rev. Saúde míbl., S. Paulo, 16:205-19, 1982.

T A B E L A 2

Reação de hemaglutinação passiva para $L$. donovani com soros absorvidos por L. donovani, L. oraziliensis e T. cruzi.

\begin{tabular}{clcccc}
\hline $\begin{array}{c}\text { Número do } \\
\text { Soro }\end{array}$ & Nome & Antes da absorção & L. donovani & \multicolumn{2}{c}{ Depois da absorção } \\
braziliensis & Truzi \\
\hline 187 & C.C.S.* & $1 / 160$ & $1 / 20$ & $1 / 20$ & $1 / 80$ \\
258 & A.L.M.* & $1 / 160$ & $1 / 40$ & $1 / 40$ & $1 / 80$ \\
316 & D.S.* & $1 / 160$ & $1 / 40$ & $1 / 40$ & $1 / 160$ \\
$\begin{array}{c}\text { Controle } \\
\text { Calazar }\end{array}$ & F.O.** & $1 / 160$ & $<1 / 20$ & $1 / 40$ & $1 / 160$ \\
\hline
\end{tabular}

* Utilizado o soro colhido em junho de 1981.

* Utilizado o soro colhido em novembro de 1980.

T A B E L A 3

Reação de inibição da hemaglutinação para $L$. donovani com antígenos de $L$. donovani e $T$. cruzi.

\begin{tabular}{clccc}
\hline $\begin{array}{c}\text { Número dos } \\
\text { Soros }\end{array}$ & Nome & Hemaglutinação & $\begin{array}{c}\text { Inibição da } \\
\text { L. donovani }\end{array}$ & $\begin{array}{c}\text { Hemaglutinação } \\
\text { T. cruzi }\end{array}$ \\
\hline 187 & C.C.S.* & $1 / 160$ & $1-1$ & $1 / 80$ \\
258 & A.L.M.* & $1 / 160$ & $1-$ & $1 / 40$ \\
264 & S.F.* & $1 / 80$ & $1-$ & $1 / 20$ \\
316 & D.S.* & $1 / 160$ & $1-$ & $1 / 20$ \\
$\begin{array}{c}\text { Controle } \\
\text { Calazar }\end{array}$ & F.O.** & $1 / 160$ & $1 / 20$ & $1 / 80$ \\
\hline
\end{tabular}

* Utilizado o soro colhido em junho de 1981.

** Utilizado o soro colhido em novembro de 1980 .

vidos por $T$. cruzi. Também ocorreu total inibição da hemaglutinação quando se usou $o$ antígeno de $L$. donovani e inibição apenas parcial com $T$. cruzi.

Inquérito na população humana com intradermoreação de Montenegro - Duás pessoas apresentaram reação positiva $(8 \mathrm{~mm})$. Trata-se de adultos procedentes da Bahia, residentes no local há 2 e 10 anos, respectivamente. Nos testes de hemaglutinação apresentaram titulo $<40$; no teste de imunofluo- rescência os soros não foram reagentes. 0 exame físico nada revelou de anormal.

\section{Inquérito sorológico em população canina}

Nenhum dos 14 cachorros investigados apresentou resultado positivo no teste de imunofluorescência indireta. $\mathrm{Em}$ um dos cães foi observado título 20 , tendo sido o exame repetido com o mesmo resultado. A pesquisa da leishmania em pele de orelha deste animal foi negativa (exame direto, após cultura e inoculação em hamsters). 
IVERSSON, L.B. et al. Investígação epidemiológica de um novo caso de leishmaniose visceral ocorrido na Grande São Paulo, Brasil. Rev. Saúde públ., S. Paulo, 16:205-19, 1982.

Pesquisa entomológica - Observou-se que a reserva florestal está completamente alterada, tendo sido cortada parte da vegetação baixa e arbustiva. A área central da mata foi derrubada para plantio de cereais, de tal forma que a reserva atual é um circulo de mata que vista do lado de fora parece ter grandes proporçōes.

T A B E I A 4

Exemplares capturados na Barraca de Shannon. mata do bairro de Capão Redondo, São Faulo.

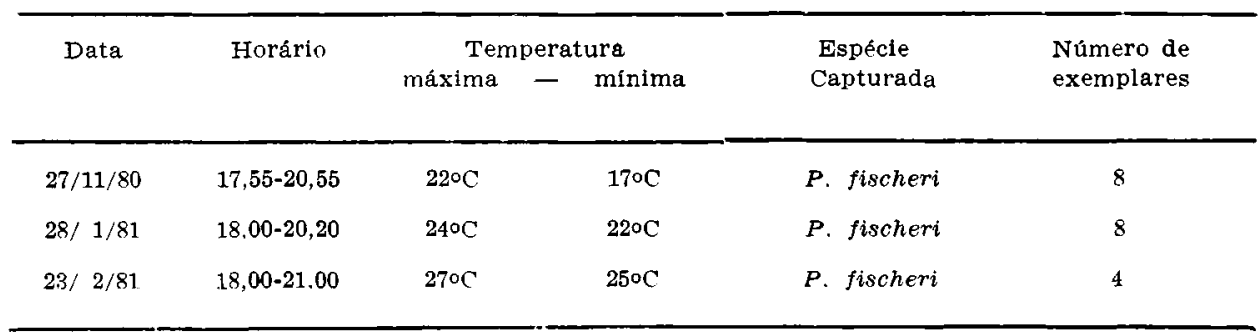

\section{COMENTÁRIOS E CONCLUSÕES}

O doente investigado, a semelhança de um dos casos de calazar anteriormente mencionados, recebeu transfusões de sangue proveniente de doadores remunerados que não foram localizados.

Com os elementos disponíveis năo pode ser eliminada a possibilidade de ter ocorrido transmissão transfusional da leishmaniose visceral. É bem verdade que o encontro do parasita no exame direto do sangue periférico de pacientes, na região neotropical, não é usual (Deane e col.1. ${ }^{5}, 1938$; Deane e Deane 13, 1955; Sherlock ${ }^{37}$, 1964; Torrealba ${ }^{40}, 1970$ ), ao contrário de que sucede no calazar indiano em que, desde 1904 quando Christophers ${ }^{10}$ relatou a presença do parasita em sangue periférico, essa parasitemia tem sido assinalada de forma constante, com alta freqüência e intensidade (Donovan ${ }^{16}$, 1905; Patton ${ }^{31}$, 1914; Mackie ${ }^{2 \tau}$, 1915; Knowles ${ }^{23}$, 1920; Young e Van Sant ${ }^{41}$, 1923; Knowles e Das Grupta 2+, 1924; Short e col. ${ }^{38}, 1927$ ).

As observações ocasionais de alguns pesquisadores revelam que a leishmaniose visceral neotropical, embora as leishmanias sejam raras no sangue circulante, elas estão presentes, uma vez que a hemocultura (Deane e Deane 13, 1955) ou a inoculação em hamster (Torrealba to, 1970) mostram resultados positivos freqüentemente.

Um argumento desfavorável a ser lembrado em relação à probabilidade da transmissão da parasitose por via transfusional é que a proporção de adultos doentes, possiveis fontes de infecção como doadores de sangue, é baixa, uma vez que $81 \%$ a $83 \%$ dos casos da moléstia, nas áreas de maior endemicidade no país, ocorrem em urianças menores de 10 anos de idade (Alencar e col.23, 1956, 1975).

Existia, no entanto, em nosso meio na época do fato assinalado, um risco grande a ser levado em consideração de se poder adquirir infecções por via transfusional. Até 30 de abril de 1980, quando a Portaria Interministerial n? 7/BSB estabeleceu as Diretrizes Básicas do Programa Nacional de Sangue e Hemoderivados, Pró-Sangue, que prcconiza a coleta de sangue só em doadores voluntários, o doador remunarado representava uma parcela significativa no abastecimento dos Bancos de Sangue do país. O sangue desse individuo, de baixa condição socio-econômica-cultural, procedente de áreas rurais onde grassavam 
IVERSSON, L.B. et al. Investigação epidemiológica de um novo caso de leishmaniose visceral ocorrido na Grande São Paulo, Brasil. Rev. Saúde puibl., S. Paulo, 16:205-19. 1982.

diversas endemias, constituia-se em fonte de infecção comprovada e relevante dessas moléstias. Amato Neto * (1979), estima, baseado no número anual de transfusões realizadas no país, aproximadamente 4.000 .000 , e na proporção de doadores infectados pelo $T$. cruzi, que ocorriam cerca de 20.000 casos anuais de doença de Chagas transfusional. Camargo e Leser : (1974), ao relatarem dois casos de doenças de Chagas pós-transfusional, ocorridos em hospitais de alto padrão da cidade de São Paulo, chamam a atenção para a "urgência da fiscalização mais rigorosa de antígenos e reagentes comercializados, de qualidade muito variável e freqüentemente sujeitos a deterioração que passa despercebida aos técnicos que realizam os testes". Em se tratando de leishmaniose visceral não há legislação em vigor que proiba um individuo com antecedente da moléstia, de ser doador de sangue (Ministério da Saúde 2^, 1977; Secretaria de Estado da Saúde 3 st, 1979). Há, no entanto, publicações referentes a ocorrência de calazar pós-transfusional em outros países. Chung e col. ${ }^{11}$ (1948) relatam pela primeira vez esse fato em duas irmãs de quatro e seis anos de idade que haviam sido inoculadas por via intramuscular com $20 \mathrm{ml}$ de sangue da mãe doente, 9 a 10 meses antes dos primeiros sintomas da moléstia. André e col. ${ }^{\circ}$ (1957) e Cayla e col.9 (1957) descrevem o caso de um recém-nascido que recebeu uma exosangüi-neo-transfusão onde foi utilizado sangue de doente $e$ que 8 meses depois apresentou leishmaniose visceral. Nas situações mencionadas houve um atento seguimento das crianças transfundidas, pois o diagnóstico da doença nas fontes de infecção foi realizado após a administração do sangue.

É possível que quando esse estado de alerta não tenha se estabelecido, a via de transmissão ou a própria moléstia possam não ter sido identificadas. Abdalla 1 (1980), em área endêmica do Sudão, encontrou 3,3\% de soros com reações de imunofluorescência indireta positivas para $L$. donovani entre 300 doadores de sangue aparentemente sadios. Embora São Paulo não seja área endêmica, uma parte da população de doadores que abastecia seus Bancos de Sangue possivelmente provinha de áreas endêmicas.

Concluindo, a única forma de se excluir a transmissão transfusional na criança investigada seria á certeza inequivoca de ter ocorrido transmissão natural.

Os dados sorológicos sugerem que 5 das 344 pessoas pesquisadas apresentaram titulos de anticorpos compativeis com o diagnóstico de infeç̧ão leishmânica. A ausência de sintomas e sinais clinicos leva a pensar em infecções subclínicas. O fato de três dessas pessoas sempre terem vivido no município de São Paulo induz a pensar em infeç̧ões autóctones.

Os testes de absorção dos soros com $T$. cruzi, $T$. donovani e L. braziliensis preconizados por Camargo e Rebonato ${ }^{*}$ (1969) e os testes de inibição de hemaglutinação para $L$. donovani utilizando $L$. donovani e $T$. cruzi, realizados com a finalidade de remover a reatividade heteróloga, permitiram eliminar a possibilidade de infecção por $T$. cruzi, mas não $O$ fizeram para $L$. braziliensis. Considerando a inexistência de lesões cutâneas e mucosas nos investigados e 0 antecedente epidemiológico, poderia ser considerada a probabilidade de se tratar de infecção por $L$. donovani.

A ausência das reações intradérmicas positivas, usualmente observadas em assintomáticos residentes em regiões onde a leishmaniose visceral é endêmica e onde não se encontra leishmaniose tegumentar (Pampiglione e col.29.30, 1974, 1975; Teixeira $\left.{ }^{39}, 1977\right)$, não invalida essa probabilidade, pois a positividade não é achado obrigatório nos doentes após a cura.

Da mesma forma não o fazem a não localização de reservatório infectado no limitado inquérito realizado em população canina ou a ausência de vetor conhecido, $L$. longipalpis, nas raras capturas efetuadas. Uma revisão bibliográfica recente, relativa a inquéritos em cães, em áreas endêmicas da região neotropical, mostrou que a proporção de animais infectados pela $L$. donovani oscila entre $0,1 \%$ a $46,5 \%$ dos animais exami- 
IVERSSON, L.B. et al. Investigação epidemiológica de um noro caso de leishmaniose visceral ocorrido na Grande São Paulo, Brasil. Rev. Saúde pübl., S. Paulo, 16:205-19, 1982.

nados, com valores mais frequientes abaixo de $10 \%$ (Forattini 1s, 1973). De acordo com esses dados é possível não se encontrar animais infectados quando uma quantidade pequena de cães for pesquisada. Não pode ser afastada também a possibilidade de que nessa transmissão urbana da leishmaniose visceral participem roedores, presentes no local investigado.

Em relação a não identificação da $L$. longipalpis, o número de capturas realizada não autoriza uma conclusão. Além disso, outros flebotomíneos, como já suspeitado em primeiros casos da moléstia observados em outros locais do continente (Pifano e Romero ${ }^{2}$, 1964; Courmes e col.1:, 1966), podem estar envolvidos na transmissão.

Por outro lado, o aspecto paisagistico do local da residência do doente, em zona urbana da periferia do município, próximo a reserva florestal, em terreno acidentado junto a um vale, assim como as condições de temperatura e umidade apresentam similaridades com o caso autóctone da doença notificado em 1978, residente em área geográfica próxima (Iversson e col. ${ }^{2-}$, 1979).
Levando em consideração todos os dados disponiveis há indicios consistentes de que ocorreu transmissão natural da moléstia, mas não se pode afirmar. Impõe-se a necessidade de pesquisas dirigidas a reservatórios e vetores, que permitam observações em periodos longos de tempo, pois existem hiatos não preenchidos em relação a forma com que está ocorrendo a transmissão natural da leishmaniose visceral na Grande São Paulo.

\section{AGRADECIMENTOS}

Ao Dr. Mario E. Camargo, Chefe da Seção de Imunologia do Instituto de Medicina Tropical da Universidade de São Paulo, pela valiosa colaboração fornecendo globulina anti-cão e cepa de $L$ donovani.

À Dra Rosely Sichieri, Dra Vera Maria Galesi e equipe do Centro de Saúde de Santo Amaro que coletaram os dados pessoais e de exame físico das pessoas investigadas.

Ao Dr. Arnaldo Vilanova, diretor do Centro de Zoonoses de São Paulo e a $D$ a Ana Maria Frontini Soares, da mesma Instituição, pelo auxílio prestado na coleta de sangue de cães examinados.

IVERSSON, L. B. et al. [Epidemiological investigation of a new case of visceral leishmaniasis in Greater S. Paulo, Brazil]. Rev. Saúde púlbl, S. Paulo, 16:205-19, 1982 .

ABSTRACT: An epidemiological investigation was made in the urban zone of S. Paulo, Brazil, to elucidate a case of visceral leishmaniasis that occurred in a two-year old child, born and always resident in that place. The possibility of congenital transmission was eliminated. The transmission by blood transfusion and biological vector was discussed on the basis of the past history of the child and the results of a serological survery in human population with indirect imunofluorescence, passive hemagglutination and leishmanin tests, serological survey on dogs and furthermore entomological research in residual forest situated in the neighbourhood of the patient's house.

UNITERMS: Leishmaniasis, visceral. Epidemiologic surveillance. 
IVERSSON, L.B. et al. Investigação epidemiológica de um novo caso de leishmaniose visceral ocorrido na Grande São Paulo, Brasil. Rev. Saúde públ., S. Paulo, 16:205-19, 1982.

\section{REFERENCIAS BIBLIOGRAFICAS}

1. ABDALLA, R.E. Serodiagnosis of visceral leishmaniasis in an endemic area of the Sudan. Ann. trop. Med. Parasit., 74:415-9, 1980 .

ALENCAR. J.E. et al. Calazar no vale do Jaguaribe, Ceará, 1955. Rer. bras. Malar., 8:33-47, 1956.

3. ALENCAR, J.E. et al. Aspectos atuais de Calazar no Ceará. Rev. bras. Malar., $26: 27-53, \quad 1974 / 1975$

4. AMATO NETO, V. Transmissão por trans fusão de sangue. In: Congresso Internacional sobre Moléstia de Chagas, Rio de Janeiro, 1979. Anais. Rio de Janeiro, 1979. p. H.20-H.23.

5. AMATO NETO, V. \& BLANCO FILHO, F. Leishmaniose visceral adquirida no Estado de São Paulo (Brasil). Rer. Saúde publ., S. Paulo, 15:643-5, 1981.

6. ANDRÉ, R. et al. Leishmaniose cutanée. leishmaniose cutanéo-ganglionnaire et Kalazar transfusionnel. Bull. Mem. Soc. Méd. Des. Hop., 25/26:854-60, 1957.

7. CAMARGO. M. \& LESER, P.G. Diagnóstico acidental de laboratório de infecções chagásicas agudas pós-transfusionais não suspeitas. Rer. Ass, med. bras., 20:335-6. 1974.

8. CAMARGO. M.E. \& REBONATO, C. Cross reactivity in fluorescence test for Trypanosoma and Leishmania antibodies. Amer. J. trop. Med. Hyg., 18:500-5 1969.

9. CAYLA, A. et al. Sur um cas de Kala- Azar tranfusionnel chez um nourrisson de huit mois. Arch. frans. Pédiat., 14 $732-4,1957$.

10. CHRISTOPHERS. L.S.R. A preliminary report on a parasita found in persons s-ffering from enlargement of the spleen in India. Scient. Mem. Off. med. sanit. Depart. Govern. India, (8):1-17, 1904.

11. CHUNG, H. et al. The first two cases of transfusion Kala-Azar. Chin. med. J., 66:325-6. 1948.

12. COURMES, E. et al. Premier cas autochtone de Leishmaniose viscerale humaine a la Guadeloupe. Bul, Soc. Path. exot., ร9:217-25. 1966 .
13. DEANE, L.M. \& DEANE, M.P. Observações preliminares sobre a importância do homem, do cão e da raposa (Lycalopex vetulus) como reservatório de $L$. donovani, em área endemica de calazar no Ceará. Hospital, Rio de Janeiro, 48:61-76, 1955 .

14. DEANE, M.P. \& DEANE, L.M. Observações sobre a transmissão da leishmaniose visceral no Ceará. Hospital, Rio de Janeiro, 48:347-64, 1955.

15. DEANE, L.M. et al. Leishmaniose visceral americana. I - Estudos clínicos: terapêutica. Mem. Inst. Oswaldo Cruz, 33: 95-137, 1938.

16. Donovan, C. Medical cases from Madras General Hospital. Ind. Med. Gaz, 40: $411-4,1905$.

17. FERNANDES, J.F. \& CASTELLANI, O. Growth characteristics and chemical composition of Trypanosoma cruzi. Exper. Parasit., 18:195-202. 1966.

18. FORATTINI, O.P. Entomologia médica. São Paulo, Ed. Edgard Blücher/EDUSP. 1973. v.4.

19. FORATTINI, O.P, et al. Sobre o encontro de Lutzomyia lonyipalpis (Li:tz \& Neiva, 1912) no Estado de São Paulo. Brasil. Rer. Saúde púbt., S. Paulo, 4:99-100, 1970

20. FORATTINI, O.P. et al. Noros encontros de flebotomíneos no Estado de São Paulo, Brasil, com especial referência a Lutzomyia longipalpis. Rev. Saúde pübl., S. Paulo, 10:125-8, 1976.

21. Hoshino-SHIMizU, $\mathrm{S}$. et al. A stable polysaccharide - hemagglutination reagent for the diagnosis of acute on recent Trypanosoma cruzi infections. Rev. Inst. Med. trop. S. Paulo, 20:208-12, 1978.

22. IVERSSON, L.B. et al. Investigação epidemiológica de um caso de Leishmaniose visceral autóctone da Grande São Paulo. Brasil. Rev. Saúde públ., S. Paulo, 13: 159-67, 1979.

23. KNOWLES. R. A study of Kala-Azar, Ind. J. med. Res., 8:140-62, 1920 . 
IVERSSON, L.B. et al. Investigação epidemiológica de um novo caso de leishmaniose visceral ocorrido na Grande São Paulo, Brasil. Rev. Saúde pübl., S. Paulo, 16:205-19, 1982.

24. KNOWLES, R. \& DAS GRUPTA, B.M. The diagnosis of Kala-Azar by examination of tick blood films. Ind. Med. Gaz., 59: 438-40, 1924.

25. LOWRY, O.H. et al. Protein measurement with the folin phenol reagent. J. Biol. Chem., 193:265-75, 1951.

26. LUTZ, A. \& NEIVA, A. Contribuição para - conhecimento das espécies do gênero Phlebotomus existentes no Brasil. $\mathrm{Mem}$. Inst. Oswaldo Cruz, 4:84-95, 1912.

27. MAKIE, F.P. The presence of Leishmania in the peripheral blood of cases of Kala-Azar in Assam. Ind. J. med. Res. 3:90-2, 1915.

28. MINISTerio DA SAÚDE. Legislação

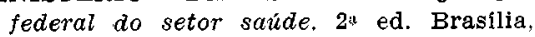
Consultoria Jurídica, 1977. v. 3.

29. PAMPIGLIONE, $\mathrm{S}$. et al. Studies on Mediterranean leishmaniasis. 2. Asymptomatic cases of visceral leishmaniasis. Trans. roy. Soc. trop. Med. Hyg., 68:447-53, 1974.

30. PAMPIgLione, $\mathbf{S}$. et al. Studies on Mediterraneam leishmaniasis. 3. The leishmanin test in Kala-azar. Trans. roy. Soc. trop. Med. Hyg., 69:60-8, 1975.

31. PATTON, W.S. The examination of the peripheral blood of 84 patients suffering from Kala Azar at the General Hospital, Madras, during the period from 15 th June, 1912 to 15 th $\mathrm{July}$, 1913. Ind. J. med. Res., 2:492-504, 1914.

32. PIFANO, C.F. \& ROMERO, M.J. Comprobacion de um nuevo foco de leishmaniasis en Venezuela, Valle de Ctmanacoa. Edo Sucre. Gac. med. Caracas, 72:473-9, 1964.

33. SALLES GOMES, L. Sobre um meio de cultura para o Haemophilus ducreyi. Alguns dados técnicos referentes ao isolamento desse bacilo. Rev. Inst. Adolfo Lutz, 20:161-76, 1960.
34. SECRETARIA DE ECONOMIA E PLANEJAMENTO DO ESTADO DE SAO PAULO. Conhesa seu Municipio: Região da Grande São Paulo. São Paulo, 1974. v. 5 , tomo 2 .

35. SECRETARIA DE ECONOMIA E PLANEJAMENTO DO ESTADO DE SÃO PAULO. Conheça seu Municipio: Região au Grande São Paulo. São Paulo, 1974. v.5. tomo 3 .

36. SECRETARIA DE ESTADO DA SAÚDE. Código Sanitário: decreto no 12.342 de 27 de setembro de 1978. São Paulo. Imprensa Oficial do Estado, 1979.

37. SHERLOCK, I. Surto de Calazar na zona central do Estado da Bahia. Rev. bras. Malar., 16:157-70, 1964.

38. SHORT, H.E. et al. The finding of parasites in the peripheral blood of Kala-Azar cases by direct microscopical examination. Ind. J. med. Res., 15:529-38, 1927.

39. TEIXEIRA, R., coord. Projeto Jacobina; relatório de atividades do periodo de maio de 1976 a dezembro de 1977. Salvador, Universidade Federal da Bahia, 1977. (CNPq - Projeto ne 5.285/75, S.I.P./08-141).

40. TORREALBA, J.W. Observaciones sobre diagnóstico, terapeutica y evolución de la Leishmaniasis visceral humana $y$ canina. Valência, 1970. [Tese - Facultad de Medicina de la Universidad Central de venezuela].

41. YOUNG, C.W. \& VAN SANT, H.M. Leishmania donovani in peripheral blood. $J$. exper. Med., 38:233-56, 1923.

Recebido para publicação em 10/02/19S2

Aprovado para publicaşão em 14/04/1982 


\section{ER R A T A}

REVISTA DE SAÜDE PÜBLICA, 16(4), 1982

p. 205 . RESUMO .. 4. linha

Onde se lê: ...Afastou-se a possibilidade de transmissão por via transfusional.

Leia-se: ...Afastou-se a possibilidade de transmissão congênita e se discutiram as hipóteses de transmissões por via transfusional.

p. 211 .. penúltima linha

Onde se lê: (Mesocricetus autoratus), sacrificados.

Leia-se: (Mesocricetus auratus), sacrificados. 
O arquivo disponível sofreu correções conforme ERRATA publicada no Volume 16 Número 4 da revista. 